\title{
BMJ Global Health Build back stronger universal health coverage systems after the COVID-19 pandemic: the need for better governance and linkage with universal social protection
}

\author{
Fabrizio Tediosi (D) , ${ }^{1,2}$ Knut Lönnroth (D) ${ }^{3}$ Ariel Pablos-Méndez, ${ }^{4}$ Mario Raviglione ${ }^{5}$
}

To cite: Tediosi F, Lönnroth K, Pablos-Méndez A, et al. Build back stronger universal health coverage systems after the COVID-19 pandemic: the need for better governance and linkage with universal social protection. BMJ Global Health 2020;5:e004020. doi:10.1136/ bmjgh-2020-004020

Handling editor Seye Abimbola

Received 21 September 2020 Revised 1 October 2020 Accepted 3 October 2020

Check for updates

C Author(s) (or their employer(s)) 2020. Re-use permitted under CC BY-NC. No commercial re-use. See rights and permissions. Published by BMJ.

${ }^{1}$ Swiss Tropical and Public Health Institute, Basel, Switzerland

2University of Basel, Basel, Switzerland

${ }^{3}$ Department of Global Public Health, Karolinska Institute, Stockholm, Sweden

${ }^{4}$ Columbia University Irving Medical Center, New York City, New York, USA

${ }^{5}$ Global Health Centre, University of Milan, Milano, Italy

Correspondence to Dr Fabrizio Tediosi; fabrizio.tediosi@unibas.ch
The need for a systemic approach to complex challenges and for better understanding the relationship between population health and its economic consequences have been recognised for years as the basis towards sustainable solutions in global health. The emergence of a movement promoting Universal Health Coverage (UHC) as the ultimate means to ensuring equitable access to health for all people, raised the attention to the importance of re-imagining health systems. The COVID-19 pandemic further highlighted the importance of UHC that should be promoted with better governance and linkages to social protection systems.

\section{UHC IS KEY TO FACE POPULATION HEALTH THREATS}

UHC is the aspiration that all people will obtain access to quality health services they need while not suffering financially as a result of paying out of pocket for health care. ${ }^{1} \mathrm{UHC}$ requires that countries expand the availability of, and effective access to, essential health services and include more people in risk pooling mechanisms, such as social or private medical insurances or tax-based prepaid systems, to reduce out of pocket payments at point of service.

The inclusion of UHC in Sustainable Development Goal 3 (SDG 3) has generated attention to coverage of essential health services, to financial protection-catastrophic or impoverishing out-of-pocket health spending-and to health system strengthening. Implicitly, it has also supported the inclusion of equity considerations into the global health agenda. Like AIDS a generation ago, UHC has re-energised the social justice driver of the
Summary box

Moving towards and sustaining Universal Health Coverage (UHC) is critically important to build resilient health systems and to promote more inclusive and fairer societies.

- The progressive realisation of UHC requires good governance and linkages with social protection systems.

- UHC policies should be coordinated with social protection systems providing social safety nets and coordinated governance is required across health and social sectors.

- This requires system-wide social and health policies breaking the boundaries of traditionally fragmented welfare systems and global health programmes.

community with greater political resonance than other health causes beyond ministries of health. Yet, as effectively demonstrated by the recent Lancet Commission on high quality health systems, there is a long way to go to strengthen health systems. ${ }^{2}$

Considering only access to medical services brings the risk of promoting what has been termed as 'volume-based health systems' that focus on quantity of medical care rather than quality or outcomes. ${ }^{3}$ The COVID-19 pandemic showed how UHC provides the foundations for resilient health systems able to face new threats to population health. However, it also highlighted the shortcomings of modern and well-resourced health systems, especially when advanced tertiary care is not matched by adequate public health, primary care and social care systems. In many countries, this imbalance meant slow implementation of essential public health measures to promote enhanced hygiene practices, isolation and physical distancing, in particular to 
protect the most vulnerable groups such as elderly people in care institutions.

A major challenge is how countries with limited resources, or under tough budget constraints, can sustain in the long-term universalistic health systems able to deal with the contemporary challenges. Most countries that have an advanced health system, such as those of western Europe, are facing challenges to financially sustain them. Also as a result of this, there are inequalities in health and in access to health services in most advanced countries, as well as high out-of-pocket payments that often cause financial hardship to the poorest population groups. ${ }^{45}$

In high-income and, increasingly, in middle-income countries the decline in fertility rates, coupled with life expectancy increases, led to ageing populations and changes in family structures, shrinking the number of people economically active and increasing the number of people in need of support from the welfare system. In addition, the technological changes with the continuous development of new medical technologies contributed to increased people expectations. In the health sector, this is particularly important as several new medical technologies are often of relatively low health value. When they are really innovative, they are usually very expensive and create financial challenges to health systems. ${ }^{6}$

Several less advanced countries that committed to move towards UHC are still far from making enough progress facing increasingly financial sustainability challenges. Health protection schemes such as health insurances can expand access to health services that are more profitable for healthcare providers, without necessarily expanding primary care or public health preventive services. This can lead to inefficient resource allocations and poorer than expected health outcomes. ${ }^{3}$

In low-income and middle-income countries, while a large part of the burden of disease is still suffered by poor populations living in deprived areas, the burden of noncommunicable diseases (NCDs) is on the rise to the point that the vast majority of deaths caused by NCDs is already today in those countries. In these same countries, health systems are largely failing to address this burden. ${ }^{78}$ This is a sufficient reason for these countries to urgently identify innovative ways to effectively include the whole population in health protection schemes-beyond providing good-quality health service through UHC policies covering the entire population or the largest part of it.

On the one hand, sustainable health protection systems must mobilise enough financial resources. On the other hand, they also have to be trusted by all the stakeholders involved and benefit from them. The only way health protection systems can meet these conditions is to respond to the evolving needs continuously modified by environmental changes, and by demographic, epidemiological, cultural and technological changes. In this respect, first the Ebola crisis in 2014 and later the COVID-19 pandemic in 2020 demonstrated the importance of building resilient health systems, ${ }^{9-11}$ able to anticipate and prepare for acute shocks, while continuously addressing the routine health needs of the population when facing these shocks. Yet, strengthening health systems resilience to shocks will require substantial longterm investments and capacity development.

Additionally, the emphasis on access to healthcare services and out of pocket medical payments may reflect a narrow view of health and of the socioeconomic risks associated with being ill. For example, employment conditions and access to adequate social insurance systems for income security affect both patients' and care workers' ability to follow public health advice to stay home when sick, self-quarantine after exposure, use healthcare and rehabilitation services.

During the COVID-19 pandemic, inadequate sickness insurance due to short-term employments and freelancing in the growing gig economy has led to presentism that fuels transmission. In non-pandemic times too, weak social protection increases risk of both impoverishment due to income loss when sick and presentism that hinders quick recovery and effective rehabilitation. Health systems strengthening therefore requires progressive realisation of both UHC under SDG 3 and universal social protection under SDG $1 .{ }^{12} 13$

\section{THE PROGRESSIVE REALISATION OF UHC REQUIRES GOOD GOVERNANCE AND LINKAGES WITH SOCIAL PROTECTION SYSTEMS}

Against this background, two crucial and interlinked issues would deserve more attention. The first is that health systems do not operate in isolation from the broader social context in which they are located. Relationships between the social protection programmes and health system actors, those within the health system and those with the population they serve, are determined and modified by the socioeconomic environment, values, social norms and standards. Understanding of the contextual factors along with a conducive health system governance and political commitment are deemed to be among the determinants of better health and the key to improve health protection performance. ${ }^{1415}$

Good governance is explicitly mentioned in SDG 16 that points to the need to 'develop effective, accountable and inclusive institutions'. ${ }^{15}$ However, the relationship between governance and health is multifaceted, including broader governance environment, public policies and those specific to the health sector, and the effectiveness of institutions or organisations. ${ }^{16}$ Governance encompasses multiple aspects, such as systems of representation and engagement for citizens, accountability mechanisms, power and institutional authority, ownership, political stability, transparency and the rule of law. It is related to how policies are formulated and implemented and how regulation is generated and exercised, as well as to the accountability mechanisms of all stakeholders. ${ }^{17-19}$ Governance is thus related to how political, economic and administrative leadership and authority are exercised within a health system. Despite 
the increasing literature on health system governance (e.g. ${ }^{16-24}$ ) documenting several governance weaknesses and the importance of it for high-quality health systems, little is known about how governance can be improved to support progress towards UHC.

The second crucial issue is the need to create better linkages and joint governance between UHC policies, focused on access to health services and to the direct expenses incurred by citizens for purchasing these services and medical products, and systems that address the full economic consequences of ill health. In fact, the social and economic burden of ill health is often much larger than that related to high out of pocket payments for medical services and products. It includes non-medical direct expenses (for travelling, food, accommodation, etc.) incurred when accessing health services, and income losses due to unpaid sick leave, disability or restrictions to the workplace due, for instance, to the risks of transmission of infection. ${ }^{12}$

Several high-burden infectious diseases such as tuberculosis, that requires a long period of treatment, or HIV/AIDS that requires lifelong medications, are associated with risks of major income losses as well as additional non-medical expenditures such as on transport and food. ${ }^{25}$ NCDs have a high social and economic burden to households facing risks of income losses. ${ }^{26}$ Caregivers of people with NCDs are more likely to be women with consequences for both childcare and female labour participation. In addition, it is likely that the economic and financial struggles due to lack of health protection are associated with long-term consequences for human capital accumulation and with productivity losses.

Health crises such as the current COVID-19 pandemic cause economic disruptions that, if not addressed, will lead to long-term increases in poverty. Weak social protection systems make people less resilient to health shocks, less able to seek care when needed, less able to follow preventive advice and more prone to economic hardship related to healthcare use (especially long hospitalisation), disability (including long sequelae) and quarantine. Poor integration (service delivery and funding streams) of health and social services (especially for the elderly) hampers implementation of pandemic/public health responses.

In addition, poor employment and working conditions in health and social services weakens infection control measures, while lack of sickness insurance (including for care staff) leads to presentism, with health consequences for the individual and poor infection control. Lastly, general lack of unemployment insurance leads to economic disaster, related to both individuals' health issues, forced quarantine and general lockdown.

The countries with stronger social protection mechanisms will be better able to mitigate these health and economic consequences, for example, through temporary adjustments to qualifiers and entitlements for income replacement during pandemics. Yet, in most low-income and middleincome countries, social protection systems are weak or in-existent, and they often rely on external donor-funded programmes with limited scope. A recent review article showed that, in most low and middle income countries, the effective coverage of the policies in place for income security is very low and existing schemes often exclude those who have the greatest need. ${ }^{27}$

\section{CONCLUSIONS}

Moving towards and sustaining UHC, as expressed in SDG 3 , is critically important to build resilient health systems and to promote more inclusive and fairer societies. Yet it will be hard to make substantial progress towards UHC without promoting simultaneously universal social protection that will contribute to realise SDG 1 targets of alleviating poverty, and stronger governance structures as indicated by SDG 16 .

UHC policies should, thus, be coordinated with social protection systems providing social safety nets, and coordinated governance is required across health and social sectors. This is a major challenge that requires system-wide social and health policies breaking the boundaries of traditionally fragmented welfare systems and global health programmes.

Twitter Fabrizio Tediosi @fabrizio2570

Contributors All coauthors contributed to conceptualise and writing the manuscript. FT wrote the first draft of the manuscript.

Funding The authors have not declared a specific grant for this research from any funding agency in the public, commercial or not-for-profit sectors.

Competing interests None declared.

Patient consent for publication Not required.

Provenance and peer review Not commissioned; internally peer reviewed.

Data availability statement This commentary has no data a part from quoting published literature.

Open access This is an open access article distributed in accordance with the Creative Commons Attribution Non Commercial (CC BY-NC 4.0) license, which permits others to distribute, remix, adapt, build upon this work non-commercially, and license their derivative works on different terms, provided the original work is properly cited, appropriate credit is given, any changes made indicated, and the use is non-commercial. See: http://creativecommons.org/licenses/by-nc/4.0/.

\section{ORCID iDs}

Fabrizio Tediosi http://orcid.org/0000-0001-8671-9400

Knut Lönnroth http://orcid.org/0000-0001-6944-0256

\section{REFERENCES}

1 Organization WH. World health report 2010. health systems financing. The path to universal health coverage, 2010. Available: http://www.who.int/whr/2010/en/

2 Kruk ME, Gage AD, Arsenault C, et al. High-quality health systems in the sustainable development goals era: time for a revolution. Lancet Glob Health 2018;6:e1196-252.

3 Kruk ME, Pate M. The Lancet global health Commission on high quality health systems 1 year on: progress on a global imperative. Lancet Glob Health 2020;8:e30-2.

4 OECD. Health at a glance, 2009.

5 Wagstaff A, Flores G, Hsu J, et al. Progress on catastrophic health spending in 133 countries: a retrospective observational study. Lancet Glob Health 2018;6:e169-79.

6 Belloni A, Morgan D, Paris V. Pharmaceutical expenditure and policies: past trends and future challenges. OECD Publishing, 2016.

7 James SL, Abate D, Abate KH, et al. Global, regional, and national incidence, prevalence, and years lived with disability for 354 diseases and injuries for 195 countries and territories, 1990-2017: a systematic analysis for the global burden of disease study 2017 . Lancet 2018;392:1789-858.

$8 \mathrm{Kyu} \mathrm{HH}$, Abate D, Abate $\mathrm{KH}$, et al. Global, regional, and national disability-adjusted life-years (DALYs) for 359 diseases and injuries 
and healthy life expectancy (HALE) for 195 countries and territories, 1990-2017: a systematic analysis for the global burden of disease study 2017. Lancet 2018;392:1859-922.

9 Hanefeld J, Mayhew S, Legido-Quigley $\mathrm{H}$, et al. Towards an understanding of resilience: responding to health systems shocks. Health Policy Plan 2018;33:355-67.

10 Kieny MP, Dovlo D. Beyond Ebola: a new agenda for resilient health systems. Lancet 2015;385:91-2.

11 Kruk ME, Myers M, Varpilah ST, et al. What is a resilient health system? lessons from Ebola. Lancet 2015;385:1910-2.

12 Lönnroth K. Medical expenditures: not the only source of financial hardship. Lancet Glob Health 2020;8:e336.

13 Lönnroth K, Tessier L, Hensing G, et al. Income security in times of ill health: the next frontier for the SDGs. BMJ Glob Health 2020;5:e002493.

14 Balabanova D, Mills A, Conteh L, et al. Good health at low cost 25 years on: lessons for the future of health systems strengthening. Lancet 2013;381:2118-33.

15 Nations U. A/RES/70/1 - Transforming our world: the 2030 agenda for sustainable development, 2015

16 Fryatt R, Bennett S, Soucat A. Health sector governance: should we be investing more? BMJ Glob Health 2017;2:e000343.

17 World Health Organization. Everybody's business: strengthening health systems to improve health outcomes, WHO's framework for action, 2007.

18 Lewis M. Governance and corruption in public health care systems Working paper 78. Washington, DC: Center for Global Development, 2006.
19 Loewenson R. Building voice and agency of poor people in health: public action within health systems. In: Bennet S, Gilson L, Mills A, eds. Health, economic development and household poverty: from understanding to action. Routledge International Studies in Health Economics, 2008.

20 Pyone $\mathrm{T}$, Smith $\mathrm{H}$, van den Broek N. Frameworks to assess health systems governance: a systematic review. Health Policy Plan 2017;32:710-22.

21 Blanchet K, Nam SL, Ramalingam B, et al. Governance and capacity to manage resilience of health systems: towards a new conceptual framework. Int J Health Policy Manag 2017;6:431-5.

22 Abimbola S. Health system governance: a triangle of rules. BMJ Glob Health 2020;5:e003598.

23 Bigdeli M, Rouffy B, Lane BD, et al. Health systems governance: the missing links. BMJ Glob Health 2020;5:e002533

24 Meessen B. Health system governance: welcoming the reboot. BMJ Glob Health 2020;5:e002404.

25 Lönnroth K, Glaziou P, Weil D, et al. Beyond UHC: monitoring health and social protection coverage in the context of tuberculosis care and prevention. PLoS Med 2014;11:e1001693.

26 Nugent R, Bertram MY, Jan S, et al. Investing in non-communicable disease prevention and management to advance the sustainable development goals. Lancet 2018;391:2029-35.

27 Thorpe J, Viney K, Hensing G, et al. Income security during periods of ill health: a scoping review of policies, practice and coverage in low-income and middle-income countries. BMJ Glob Health 2020;5:e002425 